\title{
Tarihe Tanıklık Eden Önemli Yapılar: Yalçınkaya Kaleleri (Patnos)
}

Gökhan KALMIŞ*

Mustafa KARAGEÇCi**

\author{
$\ddot{O} \mathbf{z}$
}

Anadolu coğrafyası, tarih boyunca pek çok medeniyete ev sahipliği yapan zengin bir kültür hazinesidir. Bu topraklardan gelip-geçen medeniyetler tarihe tanık izler bırakmışlardır. Doğu Anadolu Bölgesi de bu manada zengin bir tarih derinliğine sahiptir. Geç Kalkolitik Çağ'dan itibaren yerleşim görülen Patnos bölgesinde Geç Kalkolitik Çağ ve Erken Tunç Çağı'nda Karaz Kültürü hâkim olmuştur. Bu topraklara MÖ I. binyılda Urartu Krallığı hükmetmiştir. Yalçınkaya mevkiinde Geç Kalkolitik ve Erken Tunç Çağı'ndan itibaren yerleşim gören iki adet kale tespit edilmiştir. Bölgede gerçekleştirilen araştırma neticesinde bu kalelerin konumları, fiziki durumları, mimari yapıları ve keramik verilerine analitik bir şekilde yer verilmiştir. Böylece tarihe tanıklık eden iki yapının kimliği üzerinden bölge tarihine 1şık tutmak amaçlanmıştır.

Anahtar Kelimeler: Patnos, Karaz Kültürü, Urartu Krallığı, Yalçınkaya Kalesi

\section{Important Buildings Witnessing History: Yalçınkaya Castles (Patnos)}

\begin{abstract}
Anatolian geography is a rich cultural treasure that has hosted many civilizations throughout history. Civilizations that have passed through these lands have left traces of witness to history. In this regard, the Eastern Anatolia Region has a vast historical depth. In the Patnos region, which has been inhabited since the Late Chalcolithic Age, Karaz Culture was dominant in the Late Chalcolithic Age and Early Bronze Age. These lands were ruled by the Urartian Kingdom in the 1st millennium BC. Two castles, which were inhabited as of the Late Chalcolithic and Early Bronze Age, have been discovered in the Yalçınkaya locality. As a result of the research carried out in the region, the locations, physical conditions, architectural structures, and stoneware data of these castles were analyzed. Thus, it is aimed to shed light on the history of the region through the identity of the two structures that have witnessed history.
\end{abstract}

Keywords: Patnos, Karaz Culture, Urartian Kingdom, Yalçınkaya Castle

Geliş/Received: 08.10 .2021

Kabul/Accepted: 30.12 .2021

- Bu çalışma, insanlardan veri ve örnek toplamayı gerektiren, anket, inceleme, alan çalışması ve deney içeren araştırmalar kapsamına girmediğinden etik kurul onay belgesi gerektirmemektedir.

\section{Giriş}

Doğu Anadolu bölgesinin Yukarı Murat - Van bölümünde yer alan Ağrı ili; doğuda İran, kuzeyde Kars, kuzeydoğuda Iğdır, batıda Erzurum ve Muş, güneyde ise Bitlis ve Van illeri ile çevrilidir. İlin yüzölçümü 11.376 km² olup Türkiye topraklarının \% 1,4'lük kısmını oluşturmaktadır (Yazgan ve Kadanal1, 2012: 7; Kocaman ve Kaya, 2014: 17; Kaya, 2018: 1).

Ağrı ili topografyasının \% 46'sını dağlar, \% 29'unu ovalar, \% 18'ini platolar ve \% 7'sini ise yaylalar meydana getirmektedir. Bölge halkının ana geçim kaynağını tarım ve hayvancılık oluşturmaktadır. Ağrı ve çevresi, tarım açısından oldukça verimli ovalarla çevrilidir. Bu ovalar; Eleşkirt

\footnotetext{
* Dr. Öğr. Üyesi, Hatay Mustafa Kemal Üniversitesi, Fen-Edebiyat Fakültesi, Tarih Bölümü, gokhankalmis@mku.edu.tr, Orcid: 0000-0002-0118-9373

** Dr. Öğr. Üyesi, Kafkas Üniversitesi, Fen-Edebiyat Fakültesi, Tarih Bölümü, mkarageci@hotmail.com, Orcid: 0000-00026419-9325

(Makale Türü: Araştırma Makalesi)
} 
Ovası, Doğubayazıt Ovası, Tutak Ovası ve Patnos Ovası'dır. İlde, Türkiye'nin en büyük yükseltisi olan Ağrı Dağ1 (5137 m) başta olmak üzere Süphan (4058 m), Küçük Ağrı Dağı (3896 m), Tendürek (3343 m), Hama Dağı, Aşağı Dağ (3279 m), Karadağ (3250 m) ve Aladağ (3250 m) gibi önemli dağlar bulunmaktadır (Yazgan ve Kadanal1, 2012: 7).

Ağrı ili ve Patnos ilçesi, önemli yol ağlarının kavşak noktasında yer almaktadır. Geçmişten günümüze kadar yoğun bir şekilde kullanılan ticaret yollarından biri olan ve Erzurum üzerinden Tebriz'e ulaşan yol ağı oldukça stratejik bir konuma sahiptir. Bu yol, batıdan Trabzon - Gümüşhane - Bayburt Erzurum - Hasankale - Tahir Geçidi - Eleşkirt - Ağrı - Taşlçay - Doğubayazıt üzerinden gelerek Kuzeybatı İran'a ulaşmaktadır. Erzurum-Van arasındaki yol ağının en önemli durak noktalarından birini ise Patnos oluşturmaktadır (Yıldız, 1996: 60; Kocaman ve Kaya, 2014: 85; Ceylan, N. 2016: 658).

Patnos ilçesi, Ağrı il topraklarının yaklaşık \% 7,9'unu oluşturmakla birlikte $1.420 \mathrm{~km}^{2}$ 'lik bir alanı kaplamaktadır. İlçenin kuzeyinde Ağrı/Tutak ve Hamur ilçeleri, batısında Muş/Malazgirt ilçesi, güney ve güneydoğusunda Bitlis/Adilcevaz ilçesi, doğusunda ise Van/Erciş ilçesi yer almaktadır. Patnos, geniş bir alana yayılmış olan (yaklaşık $230 \mathrm{~km}^{2}$ ) Patnos Ovası üzerinde bulunmaktadır. Ovanın tarım ve hayvancılık potansiyeli oldukça yüksektir. Yükseltisi 1620-1670 m arasında değişen ova, kuzeyde Aladağlar ve güneyde Süphan Dağı arasında yer almaktadır (Yıldız, 1996: 1 vdd.).

Bir bölgenin yerleşim yeri olarak tercih edilmesinde, bölgedeki su kaynaklarının bolluğu, coğrafi konum, iklim, verimli tarım arazilerinin varllğg 1 ve önemli yol güzergâhlarına yakınlığ gibi etkenler önemli rol oynamaktadır. Çalışma sahasını oluşturan Patnos ilçesi de bu özelliklerin birçoğunu bünyesinde buludurduğu için tarih öncesi çağlardan itibaren yerleşim görmüştür. Bölgenin en önemli akarsu ağını, Fırat Nehri'nin iki önemli kolundan birisi olan Murat Nehri ve kolları oluşturmaktadır. Nehir, Van Gölü'nün kuzeyindeki Aladağ ve kuzeybatısındaki Muratbaşı Dağı'nın yamaçlarından kaynağını alan suların toplanmasıyla meydana gelmektedir. Diyadin ilçesinden sonra batıya doğru yönelen nehir, Taşlıçay’ın etrafından geçerek Ağrı il merkezi yakınlarında Eleşkirt Ovası'ndan gelen suları da toplayarak güneybatıya yönelir. Ağrı'ya kadar birçok yan kollar ve batıdan gelen Şeryan (Güzeldere) Çayı'nı da alarak büyüyen nehir, Ağrı'nın güneyinde kuzeydoğu-güneybatı doğrultusunda akarak Hamur Boğazı'na girer. Nehir daha sonra Malazgirt ve Bulanık yakınlarından geçerek Muş Ovası'na dâhil olur. İldeki önemli su kaynaklarından bir diğeri de Balık Gölü’dür. Taşlıçay ve Doğubayazıt ilçelerinin kuzey sınırında 48 km'lik bir alana sahip olan göl, ilin en büyük gölü konumundadır (Kaya, 2001: 82 vd.; 2012 Yı1ı Ağrı İl Çevre ve Durum Raporu; Kaya, 2018: 23).

\section{Patnos ve Yakın Çevresinin Eskiçağ Tarihi}

Patnos ve çevresi, Geç Kalkolitik ve Erken Tunç Çağı boyunca Karaz Kültürü'nün yayılım alanı içerisindedir. Karaz Kültürü; Transkafkaya, Kuzeybatı İran, Amik Ovası, Suriye ve Filistin'e kadar merkez Doğu Anadolu olmak üzere geniş bir yayılım coğrafyası içerisinde birçok isim ve kökenle varlığını göstermektedir. Mimari özellikleri ve kendine has keramiği ile ön plana çıkan Karaz Kültürü, 
araştırma sahasında da yoğun bir şekilde yaşanmış olup bu döneme tarihlendirilen yerleşimler, yapılan yüzey araştırmaları ve bilimsel kazı çalışmalarıyla tespit edilmiştir. Ayrıca yapılan son çalışmalarla bu kültürü oluşturanların Hurriler olduğu ifade edilmektedir (Bittel, 1945: 94; Koşay ve Turfan, 1959: 349 vd.; Piotrovskii, 1962: 7; Burney ve Lang, 1971: 43 vd.; Arsebük, 1974; Pehlivan, 1984: 170; Pehlivan, 1990: 168 vd.; Sagona ve C. Sagona, 2001: 129 vd.; Badalyan, 2014; Sagona, 2014: 30; Ceylan, 2015: 477 vd.; Üngör, 2019: 757; Sagona ve Zimansky, 2015: 167; Bingöl, 2016: 488-491; Ceylan, Özgül ve Kalmış, 2019: 27-31; Morkoç ve Alkan, 2021: 75).

Bölge hakkındaki yazılı kaynakları, MÖ I. binyılda Urartu Devleti’nin bölgeye yapmış olduğu sefer yazıtları oluşturmaktadır. Doğu Anadolu bölgesinin yüksek yaylalarında yaşayan Hurri kökenli boylar ve akraba topluluklar, Hurri-Mitanni Devleti'nin tarih sahnesinden çekilmesiyle bir beyin etrafında toplanmışlardır. Bu topluluklar, artan Asur tehlikesi sonucunda MÖ XIII-IX. yüzyıllar arasında hüküm süren "Uruatri-Nairi Konfederasyonu”nu' oluşturmuşlardır (Tarhan, 1978: 6; Tarhan, 1982: 70 vd.; Pinarcık, 2014: 36; Ceylan, 2015: 488).

Uruatri-Nairi Konfederasyonları, MÖ IX. yüzyılın sonunda güçlü düşmanları Asur’a karşı birleşerek MÖ 858 yılında Urartu Devleti'ni meydana getirmişlerdir. Urartu Devleti, bölgedeki hâkimiyetini sağlamlaştırmak, yapılan seferlerde lojistiği ve güvenliği sağlamak amaçlarıyla stratejik yerlere kaleler, gözetleme kuleleri, sulama kanalları ve garnizonlar inşa etmişlerdir. Patnos ilçesinde tespit edilen Aznavurtepe Kalesi ve Giriktepe Höyüğü’nde, bilimsel kazı çalışmaları gerçekleştirilmiştir (Balkan, 1960: 133-158; Burney ve Lawson, 1960: 192 vd.; Ceylan, N. 2020: 363). Bu kazılarda, Urartu sur duvar kalıntıları, Urartu saray malzemeleri ve yazıtlar tespit edilmiştir. Bu verilerden hareketle, Urartu Devleti'nin bölgeye büyük önem verdiği anlaşılmaktadır (Tarhan, 1978; Ceylan, 1994; Salvini, 2006; Ceylan, 2015: 486 vd.; Günaşd1, 2016: 113 vd.; Özgül, 2016: 137 vd.; Morkoç, 2020b: 111 vd.).

Urartuların, bölgedeki siyasi ve kültürel faaliyetleri ile ilgili bilgi sahibi olduğumuz yazıtlar büyük öneme sahiptir. Ağrı il ve ilçelerinde çok sayıda önemli Urartu yazıtı tespit edilmiştir. Bunlardan hem Pirabat Yazıtı'nda (Eleşkirt ilçesinde tespit edilen ve günümüzde Erzurum Müzesi'nde bulunan) hem de Patnos ilçesinde Ziyarettepe'de tespit edilen (günümüzde Van Müzesi’nde bulunan) yazttlarda aynı ifadelere yer verilmiştir: "Tanrı Haldi’nin kudretiyle İ̌spuini oğlu Menua bu kaleyi kusursuz bir şekilde yaptırdı. İšpuini oğlu Menua güçlü kral, büyük kral, Biainili Ülkesi’nin kralı ve Tušpa Şehri’nin kahramanıdır" (König, 1955-57: 302, no. 3, 4; Melikişvili, 1960: no. 1; Başgelen, 1985: 16; Dinçol, 1989: 137-139; Payne ve Ceylan, 2003: 191-201; Payne, 2006: 5.3.4, 5.3.5, 5.3.9; Günaşd1 ve Küçükyıldız, 2021: 558).

Araştırma sahasını oluşturan Patnos ve çevresindeki Urartu buluntuları üzerinde durmak, konunun daha iyi anlaşılmasını sağlayacaktır. Bu bağlamda Ziyarettepe'de ele geçirilen İšpuini

\footnotetext{
${ }^{1}$ Urartu siyasi tarihinin birinci aşamasını oluşturan bu dönem için, "Urartu'nun Beylikler Dönemi”, "Urartu'nun Arkaik Çağı”, "Urartu'nun Prehistoryası", "Urartu'nun Proto Tarihi" veya "Kavimler Birliği”" gibi farklı isimlendirmeler kullanılmıştır. Geniş bilgi için bkz. Tarhan, 1978: 85; Ceylan, 1994: 167; Çilingiroğlu, 1994: 24; Salvini, 1967: 32.
} 
dönemine ait yazıt dikkat çekmektedir. Yazıtta şu ifadeler yer almaktadır: "Tanrı Haldi'nin kudretiyle, Sarduri oğlu İšpuini bu ... (binayı ya da tapınağı) yaptırdı. (Burada) bunun gibi kusursuz başka hiçbir şey dikilmemiştir. Sarduri oğlu İšpuini bu ... (binayı ya da tapınağı) yaptırdı" (Hyvernat, 1892: 560565, no. 26; Sayce, 1893: no. 69; Sandalgian, 1900: no. 56: Belck-Lehmann, 1900: no. 13; Hulin, 1958: 242, no. 32; Güterbock, 1963: 268-269, no. 4; Lehmann-Haupt, 1928-35: no. 7, 9; Melikişvili, 1960: no. 14, 16; König, 1955-57: 296-297, no. 3,4; Payne, 2006: 2.1.11).

Günümüzde Van Müzesi’nde yer alan yazıtın İ̌spuini dönemine ait olduğu bilinmesine rağmen inşa yazıtının, hangi eserin inşası için hazırlandığı yazıtta meydana gelen tahribattan dolayı bilinmemektedir.

Ziyarettepe'de tespit edilen ve değirmen taşı olarak kullanılmış olan yazıtta ise şu ifadeler bulunmaktadır: "Išpuini oğlu Menua bu binay1 yaptırdı" (Sayce, 1882: no. 23; Sayce, 1893: 3-4; Hyvernat, 1892: 564, no. 24; Belck-Lehmann, 1892: 124, no. 4a; Lehmann-Haupt, 1928-35: no. 100, tab. 63; König, 1955-57: no. 2; Hulin, 1958: no. 10; Melikişvili, 1960: no. 87; Balkan, 1960: 106; Güterbock, 1963: 270; Payne, 2006: 5.4.7).

Patnos civarında tespit edilen ve günümüzde Anadolu Medeniyetleri Müzesi’nde bulunan inşa yazıtında ise şu ifadelere yer verilmiştir:

Tanrı Haldi'nin kudretiyle, Sarduri oğlu İšpuini ve İšpuini oğlu Menua tanrı Ua'nın susi'sini kusursuz bir şekilde yaptırdı. Tanrı Haldi adına, tanrı Ua adına ve Ua kapısı adına, yaşam, sevinç ve büyüklük, Sarduri oğlu İšpuini, İ̌spuini oğlu Menua ve Menua oğlu İnušpua'nın olsun. Yeni bir yapı (?) olduğu zaman, Tanrı Haldi'ye bir boğa, tanrı Ua'ya bir boğa, Ua kapısına bir koyun... kurban edilsinler. Tanrı Haldi’nin mızrağına...(Salvini, 1993: 144-148; Payne, 2006: 4.1.2).

İnşa yazıtı olan eser, Sarduri oğlu İšpuini, İšpuini oğlu Menua ve Menua oğlu İnišpua'nın ortak yazıtlarından biridir. Bu metinler, Urartuların bölgede mimarlık faaliyetlerine büyük önem gösterdiğine işaret etmektedir.

Patnos ilçesinde Urartu varlığının önemli göstergesi Aznavurtepe Kalesi'dir. Deniz seviyesinden 1848 m ve zeminden 208 m yüksekte bulunan kalede, 1957 y1lında Burney ve Lawson tarafından yüzey araştırması (Burney ve Lawson, 1960: 192-194), 1961-1963 yılları arasında K. Balkan tarafından bilimsel kazı çalışmaları yürütülmüş̧ür. Yapılan bu araştırmalar sonucunda kalenin sur duvarlarının tipik bir Urartu mimarisi olduğu anlaşılmıştır. Bunun dışında kalede Haldi Tapınağı, yazıtlar ve Urartu çömlekleri tespit edilmiştir (Balkan, 1960: 131-158; Balkan, 1964: 235-243). Kalede gerçekleştirilen kazılarda çok sayıda Urartu yazıtı tespit edilmiştir. Bu yazıtlardan birinde şu ifadeler yer almaktadır:

Tanrı Haldi’nin kudretiyle İšpuini oğlu Menua bir Haldi kapısı yaptırdı ve Aludiri Şehri’nde kusursuz bir şekilde bir kale yaptırd. 
Tanrı Haldi'nin kudretiyle, Ǐšpuini oğlu Menua, tanrı Haldi'nin buyruğu üzerine babasının tahtına oturduğu zaman, Šatiru Ülkesi ayaklandı. Tanrı Haldi kendi mızrağıyla sefere çıktı, Huradinaku Şehri’ni aldı, Gidimaru Şehri'ni aldı ve Šatiru Ülkesi’ni aldı. Tanrı Haldi güçlü ve tanrı Haldi'nin mızrağı da güçlüdür.

Tanrı Haldi'nin kudretiyle İ̌šuini oğlu Menua sefere çıktı, Huradinaku Şehri'ni ve Gidamaru Şehrini ele geçirdi. Šatiru Ülkesi'ni ve Tarzu'anana Şehri’ni aldı. Buštu Ülkesi'ne ve Malmali Ülkesi’ne doğru ilerledi. Daha önce hiçbir kral Huradinaku Şehri'ni ele geçirememişti, hiç kimse onu yağma edememişti. Tanrı Haldi onu Išpuini oğlu Menua'ya verdi. O, Huradinaku Şehri'ni ele geçirdi ve yerle bir etti.

Aynı yıl Alzi Ülkesi’nde ayaklanma oldu. Tanrı Haldi sefere çıktı. Ǐšpuini oğlu Menua için Qutume Şehri’ni yerle bir etti, Alzi Ülkesi’ni ele geçirdi ve Šašnu Ülkesi’ni ele geçirdi.

Qutume Şehri'nde bir kale yaptırdı. Tanrı Haldi ... tanrı Teiseba, tanrı Šivini (ve bütün) dünyanın tanrıları ... Ekilecek tarlalar ... bağlar ... Šurili Ülkesi’nde ... Menua'nın ... (Balkan, 1960: no. 1, res. 31-34; Melikişvili, 1971: no. 372; Payne, 2006: 5.1.13).

“2019 Yılı Ağrı İli Patnos İlçesi Yüzey Araştırması” (Ceylan, N. 2020, s. 360-373) esnasında da Aznavurtepe Kalesi'nde Erken Tunç ve Orta Demir (Urartu) Çağ’a ait keramikler tespit edilmiştir. Tüm bu veriler, bölgenin Urartular için büyük bir önem taşıdığına işaret etmektedir.

Ağrı ve çevresinin Eskiçağ Tarihi ile alakalı yapılan çalışmalar oldukça yetersizdir. Bu eksikliği gidermek ve bölge tarihine katkıda bulunmak amacıyla, 2019 yılında N. Ceylan başkanlığındaki bir ekip tarafından yüzey araştırması gerçekleştirilmiştir. $\mathrm{Bu}$ çalışma sırasında Yalçınkaya Kalesi I ve Yalçınkaya Kalesi II kalelerinde de incelemelerde bulunulmuştur (Ceylan, N. 2020: 363-364).

\section{Yalçınkaya Kalesi I}

Yalçınkaya Kalesi I, Patnos ilçesinin yaklaşık olarak 3.5 km güneyinde, Yalçınkaya köyünün ise hemen kuzeyindeki kayalık tepe üzerinde, $668 \mathrm{~m}$ rakımda yer almaktadır (Foto. 1). Kale, üzerinde yer aldığ1 anakayanın yapısına uygun bir şekilde çevresine hâkim bir konumda inşa edilmiştir. Dikdörtgen plan özelliği gösteren ve zeminden 33 m yüksekliği bulunan kale, kuzey-güney yönünde 66 $\mathrm{m}$, doğu-batı yönünde ise $26 \mathrm{~m}$ uzunluğundadır. Kalenin yüksekliği genel olarak kuzeyden güneye doğru alçalarak devam etmekte ve güney tarafı yayvan şekil almaktadır. Günümüzde savunma açısından zayıf olan güney tarafının ikinci bir sur duvarı ile güçlendirildiğini düşünmekteyiz.

Kalenin kuzey tarafı verimli tarım arazileri ile çevrili olup doğu tarafından ise Tuşpa'dan gelip Urartu'nun kuzeyine doğru giden ve günümüzde de kullanılan tarihi kara yolu geçmektedir (Belli, 1982: 180, 183- 184; Ceylan, N. 2016: 658-659). Kalenin kuzey tarafindaki kayalık üzerinde, 7 adet kaya basamağı yer almaktadır (Foto. 2). Basamakların uzunluğu $1 \mathrm{~m}$, yükseklikleri ve genişlikleri ise 40 cm'dir. Urartu kaya basamaklarına Erzincan'da Şirinlikale, Üçpınar Kalesi ve Erzurum'da Hasanbey Kalesi örnek olarak gösterilebilir. Bunlardan Erzincan-Şirinlikale'de iki su tüneli tespit edilmiş olup biri kalenin güneyinde, yay şeklinde kıvrılarak su yatağına doğru gitmektedir. Girişi ise 2,20 m genişliğe sahiptir. İkincisi ise bunun kuzey tarafında paralel olarak inşa edilmiştir. Girişi $3 \mathrm{~m}$ olup, basamakları 
25 cm derinliğindedir (Ceylan ve Bingöl, 2008: 131-132; Ceylan, N. 2018). Üçpınar Kalesi'nde de yap1 aynı olmakla beraber, su tüneli dolu olduğu için basamakların ölçüleri bilinmemektedir (Karageçi, 2020: 237-262). Hasanbey Kalesi'nde ise iç yükseklik $2 \mathrm{~m}$, genişlik 2,5 m, basamak derinliği ise $25 \mathrm{~cm}$ 'dir (Ceylan ve Günaşdı, 2018: 215). Yalçınkaya Kalesi I'de keşfedilen kaya basamakları üzerinde yaptığımız çalışmalar bu yapılar ile aynı özellikleri gösterdiğine ve benzer teknikle yapıldığına işaret etmektedir. Burada sadece ölçüleri farklılık göstermektedir. Bununla birlikte kalede yer alan kaya basamakları herhangi bir su kaynağına inmemektedir. Burada bulunan kaya basamakları daha çok kalenin üst tarafında tören alanı olarak kullanıldığı düşünülen mekâna ulaşmaktadır. Ayrıca bu mekânda 45 X $50 \mathrm{~cm}$ ölçülerinde dört adet sunu çukuru olarak kullanıldığı düşünülen oyukların bulunması bu görüşü destekler niteliktedir (Foto. 4). Zira bu sunakların Urartu açık hava tapınaklarında sıvı ve kan kullanarak libasyon yapmak amacıyla kullanıldığı bilinmektedir (Çilingiroğlu, 1997: 102). Dolayısıyla kalenin Urartular tarafından kullanıldı $\breve{g} 1$ bu yapılarla desteklenmektedir.

Kalede çok sayıda kaçak kazı izi mevcuttur. Kaçak kazıların, kalenin tahrip olmasına yol açtığı gözlemlenmektedir (Foto. 3). Kalenin etrafında, köylüler tarafından evler inşa edilmiştir. Kalenin sur duvarı inşasında kullanılan taşların, bölgedeki inşaatlarda kullanılmak üzere yöre halkı tarafından götürülmüş olduğu görülmektedir. Kalede tespit edilen keramik verileri (Foto. 8); Geç Kalkolitik, Erken Tunç (Karaz), Orta Tunç, Orta Demir (Urartu), Helenistik ve Orta Çağ dönemlerine tarihlendirilmiş̧ir (Ceylan, N. 2020: 363-364).

\section{Yalçınkaya Kalesi II}

Ağrı ili, Patnos ilçesinin yaklaşık olarak $5 \mathrm{~km}$ güneyinde, Yalçınkaya köyünün ise $1.5 \mathrm{~km}$ doğusunda yer almaktadır (Foto. 5-6). Kale, 1730 m rakıma sahip olup, zeminden 64 m yüksekliktedir. Kalenin doğu-batı uzunluğu 86 m, kuzey-güney genişliği ise 56 m'dir.

Kalenin etrafında bulunan sur duvarlarının kalınlığı yaklaşık olarak 2,90 m’dir. Kuru duvar tekniğiyle inşa edilen ve temel izlerinden takip edilen sur duvarlarının en dik tarafı kalenin kuzey tarafindadır. Zira bu yöndeki sur duvar taşları, kalenin alt tarafına kadar yuvarlanmıştır. Sur duvar yapımında kullanılan taşların boyutları 130 x $75 \mathrm{~cm}, 100$ x $90 \mathrm{~cm}$ ve 90 × $70 \mathrm{~cm}$ arasında değişmektedir. Kaleye, doğu tarafında bulunan 5,50 cm genişliğinde ve 4,60 cm uzunluğundaki bir giriş kapısı ile girilmekte ve kaleye girildikten sonra geniş düzlük bir alanın varlığı dikkat çekmektedir. Bu yöndeki sur duvarları da temel izlerinden takip edilebilmektedir. Ayrıca kalenin doğu tarafında nekropol olarak kullanıldığı düşünülen bir alan mevcuttur. Yakın bir tarihe kadar bu alanın iş makineleri ile tahrip edildiği görülmektedir. Kalenin kuzeybatısı ve batısı geniş tarım arazileri ile çevrilidir.

Kalede tespit edilen keramik verileri; Erken Tunç, Erken Demir ve Orta Çağ dönemlerine tarihlendirilmektedir. Ayrıca kalede, çok sayıda volkanik cam olarak tanımlayabileceğimiz obsidiyen parçası bulunmaktadır (Foto. 9). Kalede tespit edilen işlenmiş obsidiyen parçaları, kalenin obsidiyen işleme merkezi olarak kullanıldığını göstermektedir. Bölge, obsidiyen yatağı açısından da oldukça 
zengin bir yapıya sahiptir (Ceylan, N. 2020: 364). Yalçınkaya I Kalesi ile oldukça yakın olmasına rağmen buradaki çalışmalarda Urartu keramiği tespit edilememiştir. Bununla birlikte kalenin konumu dikkate alındığg zaman kalenin çevresindeki tarım arazilerini ve yolu kontrol altında tutmak amaciyla inşa edildiği söylenebilir. Günümüzde dahi kalenin çevresinde hem tarım hem de hayvancılık faaliyetleri yürütülmektedir.

\section{Değerlendirme}

Yalçınkaya Kalesi I'de tespit edilen keramik verilerinden hareketle kalenin inşasının Geç Kalkolitik Çağ'da gerçekleştirildiğini, daha sonraki dönemlerde ise (Erken Tunç, Orta Tunç, Orta Demir, Helenistik ve Orta Çağ) onarım yapılarak kullanılmaya devam ettiğini ifade etmek mümkündür. Kalede sur duvarı bulunmakla beraber, tamamen tahrip olduğu için değerlendirmesi yapılamamıştır. Ancak kalede tespit edilen kaya basamaklarının, Şirinlikale, Üçpınar ve Hasanbey kalelerinde tespit edilen kaya basamaklarıyla aynı yapım tekniğine sahip olduğu görülmüştür. Kalede yapılan çalışmalarda Urartu keramiklerinin de tespit edilmesi, kalenin bir dönem Urartu hâkimiyeti gördüğünü göstermektedir. Patnos, Urartu hâkimiyetine ilk giren yerler arasındadır. Nitekim bölge Tuşpa’ya yakın olmasının da etkisiyle, İşpuini-Menua dönemlerinde Urartu hâkimiyetine girmiştir. Dolayısıyla aynı dönemde kale, stratejik konumu nedeniyle kullanılmaya başlanmış olmalıdır. Yalçınkaya Kalesi II'deki keramik verilerine göre ise kalenin yapılış tarihi Erken Tunç Çağı'na aittir. Kale, Yalçınkaya Kalesi I gibi daha sonraki dönemlerde de (Erken Demir ve Orta Çağ) onarılarak kullanılmaya devam edilmiştir.

Bulundukları coğrafyaya hâkim bir konumda yer alan Yalçınkaya Kaleleri, çevrelerindeki kara yolu ve verimli tarım arazilerini kontrol altında tutmaktadırlar. Doğa olayları ve insan eliyle gerçekleşen tahribatlar, kalelerin tarihi dokusuna büyük oranda zarar vermiştir. Yalçınkaya Kalesi I, köye yakın bir konumda yer aldığından dolayı, kalenin sur duvarı yapımında kullanılan taşların köyde inşa edilen evlerin duvarlarında kullanılmak üzere götürüldüğg̈ görülmektedir. Ayrıca kalelerde yapılan büyük çaplı kaçak kazılar, kalelerin zarar görmesinde önemli rol oynamıştır. Özellikle Yalçınkaya Kalesi II'de, iş makineleriyle gerçekleştirilen kazılar, kaleyi büyük ölçüde tahrip etmiştir. Yalçınkaya Kalesi I ve Yalçınkaya Kalesi II'de, yetkililer tarafından gerekli önlemler alınmadığı takdirde her geçen gün kaçak kazı çukurlarının sayısındaki artış devam edecektir. Binlerce yıldır varlığını koruyarak günümüze kadar ulaşmış olan bu güzide yapılar, maalesef yoğun tahribata maruz kaldıklarından dolayı kaçınılmaz bir son olarak yıkılmaktan/yok olmaktan kurtulamayacaklardır. Günden güne daha fazla tahribata uğrayan kalelerde bilimsel kazı çalışmaları neticesinde, bölge tarihi açısından önemli verilerin elde edileceği kanaatindeyiz.

Yazar Katkısı: Bu çalışmada yazarların çalışmaya katkısı eşittir.

Çıkar Beyanı: Yazarlar arasında çıkar çatışması bulunmamaktadır.

\section{Kaynakça}

Ağrı Çevre ve Şehircilik İl Müdürlüğü, (2013). 2012 yılı Ağrı il çevre durum raporu. 
Arsebük, G. (1974). Altınova'da koyu yüzlü açkılı ve karaz türü çanak çömlek arasındaki ilişkiler sorunu (Doktora tezi). İstanbul Üniversitesi Sosyal Bilimler Enstitüsü, İstanbul.

Badalyan, R. S. (2014). New data on the periodization and chronology of the Kura-Araxes culture in Armenia. Paléorient (40), 71-92.

Balkan, K. (1960). Patnos yakınında Anzavurtepe'de bulunan Urartu tapınăg 1 ve kitabeleri. Anatolia (5), 133-158.

Balkan, K. (1964). Patnos'ta keşfedilen Urartu tapınağı ve Urartu sanatı, Atatürk Konferansları I, 235243.

Başgelen, N. (1985). Doğu Anadolu'dan Demir Çağı'na ait bazı yeni bulgular 1: kitabeler-kaya tünelleri. Arkeoloji ve Sanat, 28(30), 15-18.

Belck, W.\& Lehmann C. F. (1892). Über neuerliche aufgefundene keilinschriften in Russisch und Türkisch Armenien. ZE (24), 122-152.

Belck, W.\& Lehmann, C. F. (1900). Bericht über die armenische forschungsreise der H. Hrn. W. Be1ck und C. F. Lehmann, VBGAEU (32), 29-66,430-439.

Belli, O. (1982). Urartular. Anadolu uygarlıkları ansiklopedisi I içinde (s. 139-208). İstanbul: Görsel Yayınlar.

Bingöl, A. (2016). Kars ve Çevresinde Karaz Yerleşmeleri. Kafkas Üniversitesi Sosyal Bilimler Enstitüsü Dergisi (18), 487-502.

Bittel, K. (1945). Önasya tarih öncesi çağlar: Mısır, Filistin, Suriye. İstabul: Horoz Basımevi.

Burney, C. A. ve Lang, D. M. (1971). The peoples of the hills, ancient Ararat and Caucaus.

Burney, C. A. ve Lawson, G. R. J. (1960). Measured plans of Urartian fortresses. AS (10), 177-196.

Ceylan, A. (1994). M.Ö. II. binde devletler arası ilişkiler (Doktora tezi). Atatürk Üniversitesi Sosyal Bilimler Enstitüsü, Erzurum.

Ceylan, A. (2015). Doğu Anadolu araştırmaları II (Erzurum-Erzincan-Kars-Iğdır 2008-2014). Erzurum: Atatürk Üniversitesi Yayınları.

Ceylan, A. ve Bingöl, A. (2008). 2006 yılı Erzincan, Erzurum, Kars ve Iğdır illeri yüzey araştırmaları. Araştırma Sonuçları Toplantısı 25(3), 129-149. Erzurum.

Ceylan, A. ve Günaşd1, Y. (2018). Erzurum'un eskiçağ kaleleri. Erzurum: Atatürk Üniversitesi Yayınları.

Ceylan, A., Özgül, O. ve Kalmış, G. (2019). Karaz Kültürü'nün Kahramanmaraş ve çevresindeki yansımaları. Uluslararası Antik Çağ Döneminde Maraş Sempozyumu, 17-18 Kasım 2017, Kahramanmaraş, Bildiriler kitabı içinde (s. 26-52).

Ceylan, N. (2016). Pasin Ovası'nın kuzeye açılan iki tarihi yolu. Uluslararası Sosyal Araştırmalar Dergisi 9(43), 656-671.

Ceylan, N. (2018). Erzurum ve Erzincan çevresindeki Urartu dönemi kaya basamaklı su tünelleri. (Baskıda), XVIII. Türk Tarih Kongresi.

Ceylan, N. (2020). 2019 yılı Ağnı ili, Patnos ilçesi yüzey araştırması. Tokat Gaziosmanpaşa Üniversitesi Sosyal Bilimler Araştırmaları Dergisi 15 (2), 360-373.

Çilingiroğlu, A. (1997). Urartu Krallığı tarihi ve sanatı. İzmir: Yaşam Eğitim ve Kültür Vakfı.

Dinçol, A. M. (1989). Yeni Urartu yazıtları ve yazıt parçaları. AnAr (11), 137-142.

Günaşd1, Y. (2016). Geçitler ülkesinde önemli bir Urartu kalesi: Avnik. TÜBA-AR (19), 113-136.

Günaşdı, Y. ve Küçükyıldız, İ. (2021). 2019 Yılı Ağrı ili, Eleşkirt ilçesi yüzey araştırması ve bir değerlendirmesi, Manas Sosyal Araştırmalar Dergisi 10(1), 557-577. 
Güterbock, H. G. (1963). Urartian inscriptions in the museum of Van. Journal of Near Eastern Studies (22), 268-272.

Hulin, P. (1958). Urartian stones in the Van Museum, AS (8), 235-244.

Hyvernat, H. (1892). Inscriptions inedites. P. Müller-Simonis (ed), Relation des missions scientiftques de MM. H. Hyvernat et P. Müller-Simonis (1888-1889), 560-565.

Karageçi, M. (2020). Erzincan'da önemli bir Urartu merkezi: Üçpınar Kalesi. Iğdır Üniversitesi Sosyal Bilimler Enstitüsü Dergisi (24), 237-262.

Kaya, F. (2001). Ağrı ovası ve çevresinin coğrafi etüdü (Doktora tezi). Atatürk Üniversitesi Sosyal Bilimler Enstitüsü. Erzurum.

Kaya, F. (2018). Ağrı ilinin coğrafi analizi. K. Karabulut (Ed.), Ağrı İlinin Sosyo-Ekonomik Profili kitabı içinde (s. 1-32). Ağrı: Ağrı İbrahim Çeçen Üniversitesi Yayınları.

Kocaman, S. ve Kaya, F. (2014). Ağrı ilinin turizm coğrafyası. Ağrı: Zafer Ofset Matbaacılık.

Koşay, H. Z. ve Turfan, K. (1959). Erzurum-Karaz kazısı raporu. Belleten XXIII (91), 349-413.

König, F. W. (1955-1957). Handbuch Der Chaldäischen Inschriften, Archiv Für Orientforschung Herausgegeben Von Ernst Weidner.

Lehmann-Haupt, C. F. (1928-35). Corpus inscriptionum chaldicarum.

Melikişvili, G. A. (1960). Urartskie klinoobraznye nadpisi.

Melikişvili, G. A. (1971). Urartskiye klinoobraznyye nadpisi 2: Otkritiya i publikatsiyi.

Morkoç, A. N. (2020). Urartu Devleti'nde kralların progaganda araçlarından biri: yazıtlar. İ. Kalaycı ve G. Kalmış (Ed.), Türk Kültürüne Hizmet: Öğr. Gör. Sadiddin Öztürk’e Armağan kitabı içinde (s. 111-138). Ankara: Gazi Kitabevi.

Morkoç, A. N. ve Alkan, Ö. (2021). Yeni bulgular ışığında Ardahan Ovası'nda önemli merkezler: Tepeler (Konk) Köyü kaleleri. Iğdır Üniversitesi Sosyal Bilimler Dergisi (28), 71-96.

Özgül, O. (2016). Erzurum'da stratejik bir Urartu kalesi: Tepeköy (Pir Ali Baba). TÜBA-AR (19), 137157.

Payne, M. R. (2006). Urartu çivi yazılı belgeler kataloğu. İstanbul: Arkeoloji ve Sanat Yayınları.

Payne, M. R. ve Ceylan, A. (2003). A new Urartian inscription from Ağr1- Pirabat. SMEA XLV(2), 191201.

Pehlivan, M. (1984). En eski çağlardan Urartu'nun yıkılışına kadar Erzurum ve çevresi (Doktora tezi). Atatürk Üniversitesi Sosyal Bilimler Enstitüsü, Erzurum.

Pehlivan, M. (1990). Karaz ve Hurriler. 100. Y11 Üniversitesi Sosyal Bilgiler Dergisi (1), 168-176.

Pınarcık, P. (2014). Urartuların başkentleri. TAD 33(56), 35-53.

Piotrovskii, B. B. (1962). The aeneolithic culture of Trans-Caucasian in the third millennium B.C., VI. International Concress of Prehistori cand Proto historic Sciences.

Sagona, A. G. (2014). The Kura-Araxes culture complex: a history of early research. A. Özfirat (Ed.), in SCRIPTA: Arkeolojiyle Geçen Bir Yaşam İçin Yazılar Veli Sevin'e Armağan kitabı içinde (s. 21-32). İstanbul: Ege Yayınları.

Sagona, A. ve Sagona, C., vd. (2001). Excavations at Sos Höyük, 1999. Kazı Sonuçları Toplantısı 22(1), 129-131.

Sagona, A. G. ve Zimansky, P. (2015). Arkeolojik veriler ışığında Türkiye'nin en eski kültürleri: M.Ö. 1.000.000-550. İstanbul: Arkeoloji ve Sanat Yayınları.

Salvini, M. (1993). Una dedica di ISpuini e Minua al Dio Ua. SMEA (31), 143-148.

Salvini, M. (2006). Urartu tarihi ve kültürü. İstanbul: Arkeoloji ve Sanat Yayınları. 
Sandalgian, J. (1900). Les inscriptions cunéiformes Urartiques: transcrites avec une triple traduction interlinéaire en Arménien classique, en Latin et en Française, suivies d'un glossaire et d'une grammaire.

Sayce, A. H. (1882). The cuneiform inscriptions of lake Van. JRAS (14), 377-732.

Sayce, A. H. (1893). The Cuneiform Inscriptions of Van, part 4. JRAS (25), 1-39 (no. 69-79).

Tarhan, M. T. (1978). M.Ö. XIII. yüzyılda "Uruatri” ve "Nairi” Konfederasyonları (Doçentlik tezi). İstanbul Üniversitesi Edebiyat Fakültesi, İstanbul.

Tarhan, M. T. (1982). Urartu Devleti'nin kuruluş evresi ve kurucu krallardan 'Lutipri=Lapturi' hakkındaki yeni görüşler. An $\operatorname{Ar}(8), 69-114$.

Üngör, İ. (2019). Kuzeydoğu Anadolu'da önemli bir demir çağı merkezi: Polat Kalesi (Kars/Arpaçay). Kafkas Üniversitesi Sosyal Bilimler Enstitüsü Dergisi (24), 755-770.

Yazgan, Ş. ve Kadanalı, E. (2012). Ağr1 ilinin kırsalwe turizm potansiyelinin değerlendirilmesi. Karamanoğlu Mehmetbey Üniversitesi Sosyal ve Ekonomik Araştırmalar Dergisi 14 (22), 510.

Yıldız, M. Z. (1996). Patnos'un şehir coğrafyası (Yüksek lisans tezi). Atatürk Üniversitesi Sosyal Bilimler Enstitüsü, Erzurum. 


\section{EKLER}

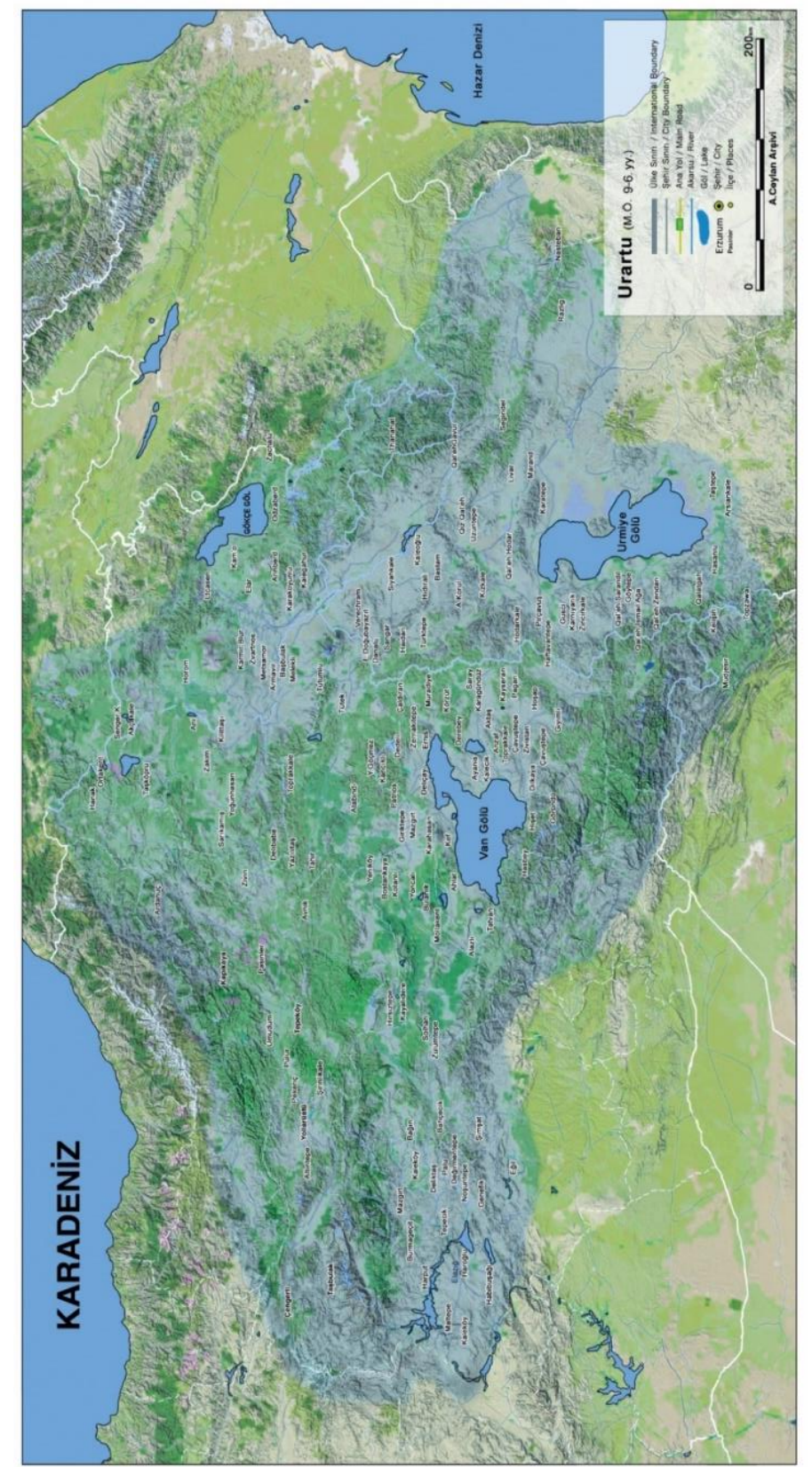

Harita 1. Urartu Yayılım Haritas1

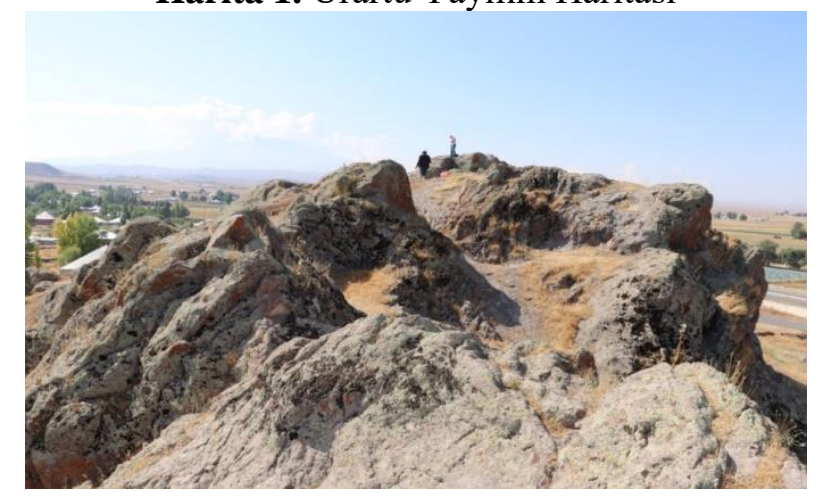

Fotoğraf 1. Yalçınkaya Kalesi I 


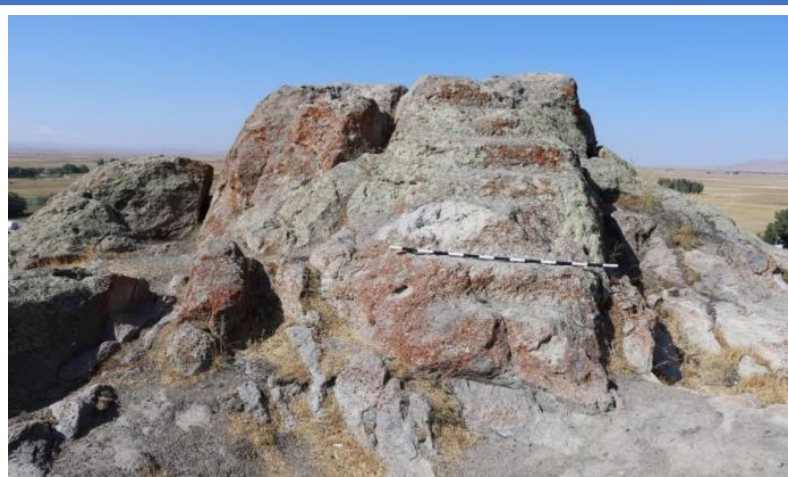

Fotoğraf 2. Yalçınkaya Kalesi I Kaya Basamakları

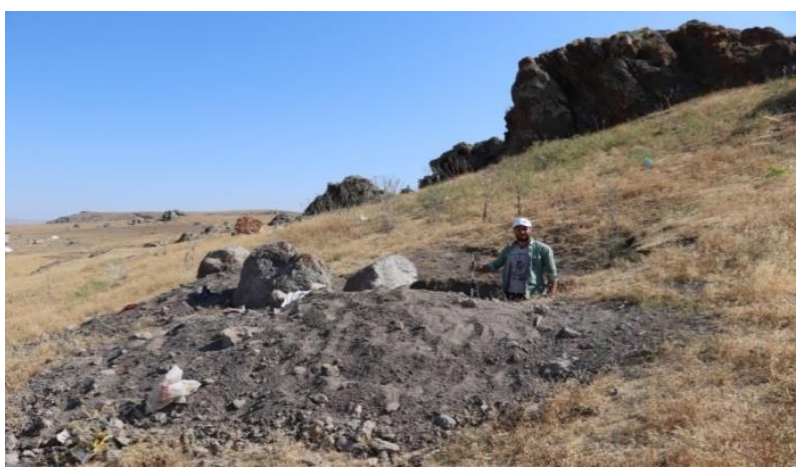

Fotoğraf 3. Yalçınkaya Kalesi I Kaçak Kazı Alanı

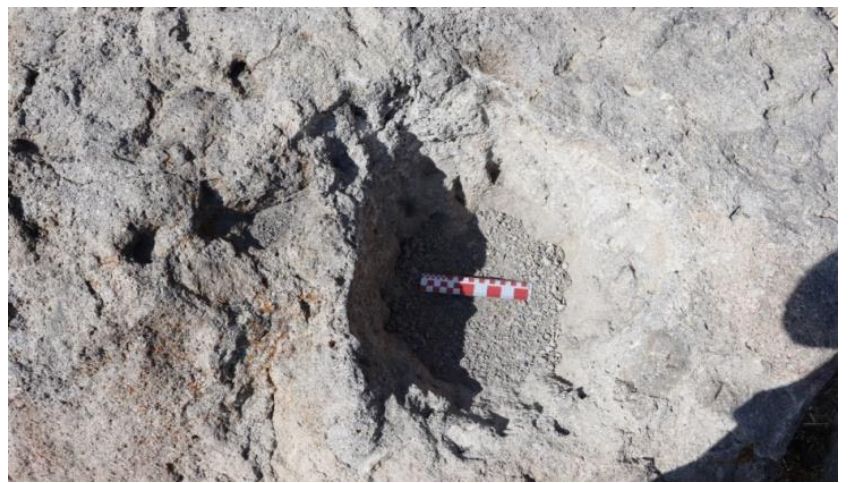

Fotoğraf 4. Yalçınkaya Kalesi I Sunu Çukuru

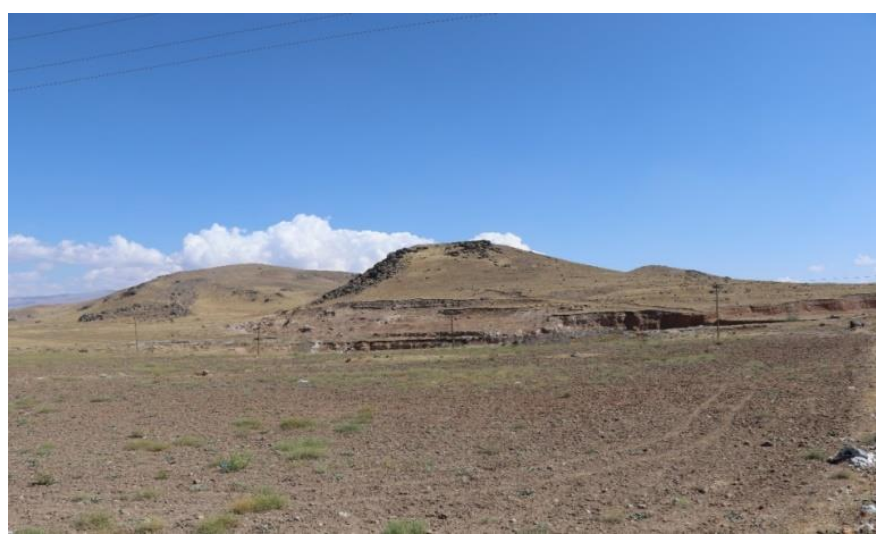

Fotoğraf 5. Yalçınkaya Kalesi II 


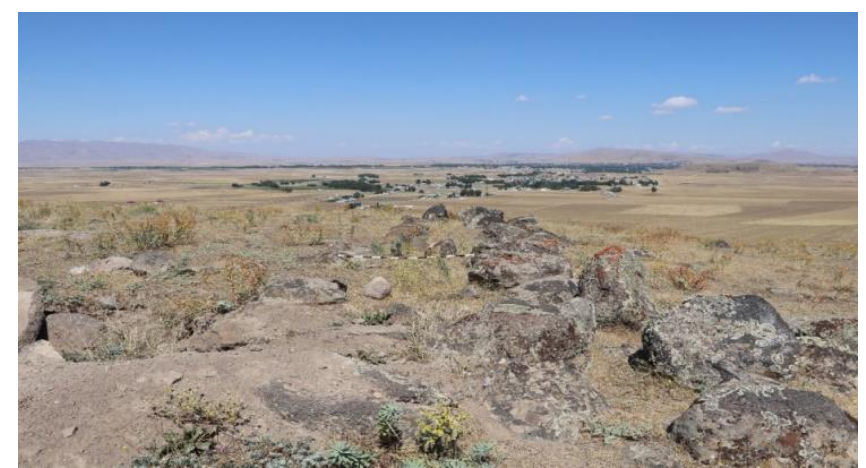

Fotoğraf 6. Yalçınkaya Kalesi II

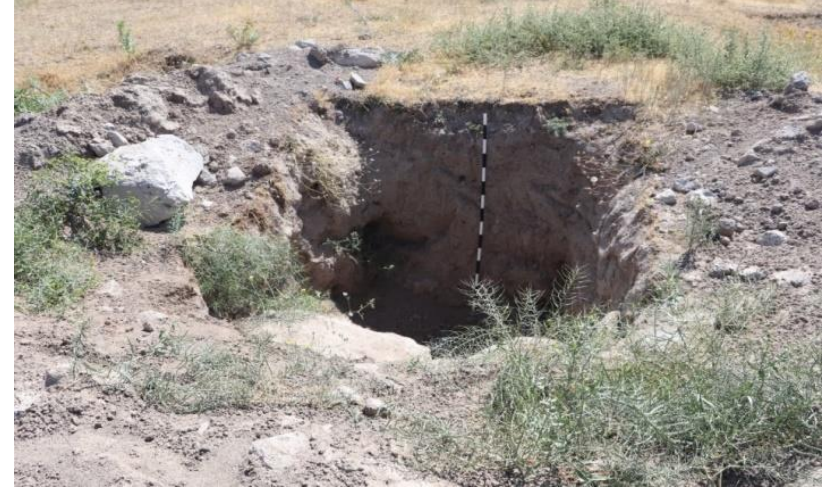

Fotoğraf 7. Yalçınkaya Kalesi II Kaçak Kazı Alanı

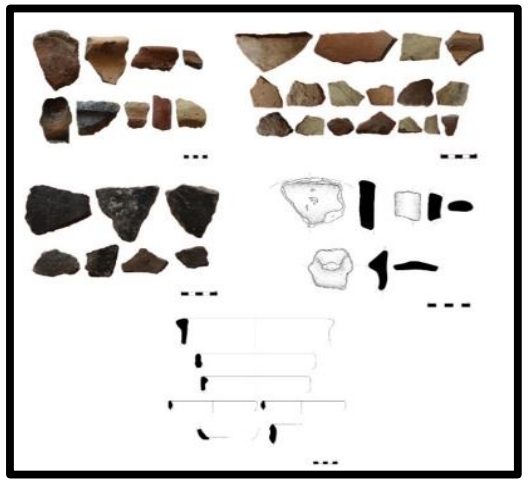

Fotoğraf 8. Yalçınkaya Kalesi I Keramik Fotoğraf ve Çizim Örnekleri

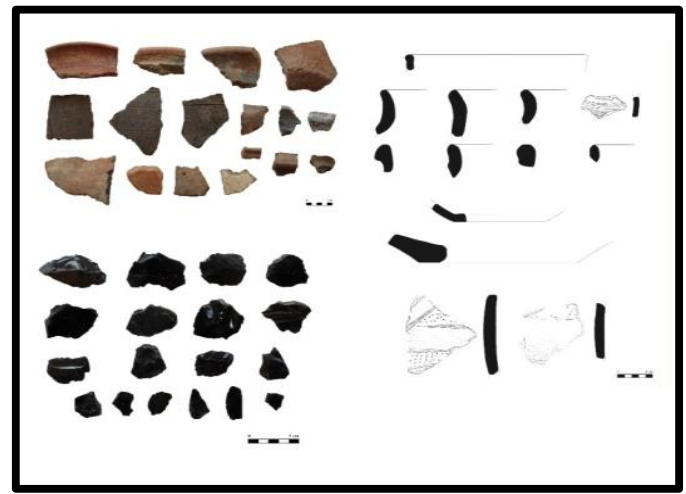

Fotoğraf 9. Yalçınkaya Kalesi II Obsidiyen, Keramik Fotoğraf ve Çizim Örnekleri 